This study is the result of a theoretical research and it aims to analyze the work of German artist Käthe Kollwitz from the perspective of engaged art. The techniques used by Kollwitz were etching, lithography, and woodcut, as well as some incursions into sculpture. All of these reveal the characteristics of clarity and of simple and unrefined strokes. Such features are linked to her wish of making art more popular and accessible to those unable to enjoy it in other spaces such as museums. Furthermore, such features are linked to her coherent belief that art should "be an event between the artist and the people". Kollwitz was inserted within the dynamics of social life and thus her commitment with the proletariat cause was attuned with art situated in the entangled daily life of workers, which was a mixture of pain, suffering, violence, and hardship. Kollwitz's refusal of conventional artistic beauty shows her vigor in contesting contrasting social inequalities, especially in Germany. She never revealed any links with political parties but her concern with the human condition was evident and it still arouses reflection regarding the future directions of contemporary art.

Keywords: Käthe Kollwitz, condição humana, 


\title{
A arte como recorte do real: a condição humana em Käthe Kollwitz
}

\author{
Rita Márcia Magalhães \\ FURTADO
}

Este trabalho, fruto de uma pesquisa teórica, tem por objetivo analisar a obra da artista alemã Käthe Kollwitz sob o viés da arte engajada. As técnicas utilizadas por Kollwitz, são a água-forte, a litografia e a xilogravura e algumas incursões pela escultura. Quaisquer delas apresentam as características da clareza, dos traços simples, sem rebuscamentos. Isso respondia a seus anseios de tornar a arte mais popular, acessível àqueles que dela não poderiam fruir em outros espaços, como os museus. Respondia também à coerência daquela que acreditava que a arte deveria "ser um acontecimento entre o artista e as pessoas". Inserida na dinâmica da vida social, seu comprometimento com a causa operária afina-se com a arte no emaranhado da vida cotidiana dos operários, mesclada pela dor, o sofrimento, a violência e a privação. A recusa da beleza da arte convencional explicita o vigor de Kollwitz em contestar a contrastante desigualdade social, especificamente na Alemanha. Sem jamais ter registrado sua vinculação a um partido político, sua preocupação com a condição humana era evidente e suscita ainda hoje em nós, o questionamento acerca dos rumos da arte na contemporaneidade.

Palavras-chave: Käthe Kollwitz, condição humana, arte social. 
A época atual parece representar a síntese de todos os paradoxos possíveis: nunca valorizamos tanto a beleza e nunca a fealdade do mundo foi tão exacerbada; nunca antes visualizamos tantas imagens e nunca nos sentimos tão cegos; nunca nos comunicamos tanto e nunca nos sentimos tão mudos; nunca ouvimos tantos ruídos e nunca nos sentimos tão surdos; nunca nossa sensibilidade esteve tão aflorada e nunca nos sentimos tão insensíveis; nunca tivemos tanto acesso a informações e nunca exercitamos tão pouco o nosso pensar. Mikel Dufrenne caracteriza esse momento contemporâneo como "deteriorização do humano" que incorre numa "perda de substância" na qual "o homem se esvazia e se aliena". No entanto assinala que as próprias causas dessa deteriorização "sugerem-nos que ela é transitória e traz em si o seu antídoto." (1998, p.217). Talvez tenha sido essa a crença de Käthe Kollwitz no exercício de sua arte, de que por ela o humano explorado se reconhecesse como capaz de mudar as condições em que vivia e o humano explorador se desse conta dos horrores de seus atos.

Passados tantos anos de distância no tempo de sua produção artística, em suas imagens, nossa visões ainda articulam sentidos e percorrem, pelo sentimento, os mesmos lugares de Kollwitz. A experiência estética não é aqui, a experiência da beleza, mas a experiência do gesto.

Nascida em Konigsberg em 1867, com uma educação que se configuraria como uma exceção para os moldes da classe média alemã da época, Kollwitz foi incentivada pela família a tornar-se artista. Inicia seus estudos na Escola das Artistas em Berlim, entre 1884 e 1885. Em 1888 vai para Munique e retorna a Konigsberg em 1890, ano em que produz suas primeiras águas-fortes.

A dúvida sobre a técnica e o estilo eram uma constante nesse período de formação. Negava-se a participar diretamente dos movimentos estilísticos, apesar da reconhecida influência dos trabalhos de Max Klinger. Nesse sentido, seu trabalho é de uma autenticidade ímpar, que reflete suas concepções políticas, sociais e de gênero. Como diz Pedrosa, não tem apuros de sentimento nem requintes intelectuais. É simples e banal, mas é imensa." (1949, p.32) 
Curiosamente Kollwitz é catalizadora de outras produções artísticas, como por exemplo, a literatura. Tal influência pode ser constatada na série intitulada Uma rebelião dos tecelões, produzida entre 1895 e 1898, que é inspirada na peça teatral Die Weber, Os teceles, de Gerhart Hauptmann, apresentada em Berlim em 1893. Outra influência citada por ela mesma, é a que se apresenta na série Guerra dos camponeses, produzida entre 1902 e 1908, baseada na leitura do livro de Wilhelm Zimmerman, Uma histria geral da guerra dos camponeses, publicado em 1841. E ainda Cena de Germinal (1893), baseada na obra Germinal de Émile Zola, escrita em 1885 e que descreve as condições subumanas de vida dos trabalhadores de uma comunidade de uma mina de carvão na França.

As técnicas utilizadas por Kollwitz, são a água-forte, a litografia e a xilogravura e algumas incursões pela escultura. Quaisquer delas apresentam as características da clareza, dos traços simples, sem rebuscamentos. Isso respondia a seus anseios de tornar a arte popular, acessível àqueles que dela não poderiam fruir em outros espaços, como os museus. Respondia também à coerência daquela que acreditava que a arte deveria ser um acontecimento entre o artista e as pessoas. Desde o início de seu trabalho, Kollwitz apreciava retratar a classe trabaIhadora, sobretudo portuária, na cidade de Konigsberg, onde morava, por ver nela uma beleza intrínseca ao gesto simples.

O casamento com o médico Karl Kollwitz em 1891 e a mudança para o bairro proletário na zona norte de Berlim são determinantes para o contato direto com os trabalhadores das indústrias têxteis e suas famílias, seu modo de vida e suas manifestações político-sociais.

Desde seu tempo de formação, Kollwitz exercia a autocrítica com relação a seu trabalho e quanto à pintura, considerava mesmo que lidar com as cores era sua maior dificuldade. A gravura, então, apresentava-se como uma boa escolha de trabalho, sobretudo depois de casada, por dois motivos: a acessibilidade a seu trabalho, estipulando preços inferiores ao do mercado convencional de artes como condição para as galeristas, possibilitando a disseminação de sua arte a um público mais vasto; e a praticidade do manuseio de lâminas que the 
parecia mais pertinente do que o das tintas, telas e cavaletes, no cotidiano tão preenchido por atividades domésticas.

A perda precoce de um filho na Primeira Guerra Mundial e um neto na Segunda Guerra Mundial exacerba ainda mais a dor e a angústia de Kollwitz diante da desumanidade dos homens que promovem a guerra.

A presença do feminino, no conjunto de sua obra, denota a rejeição da condição de passividade, de mero adereço como comumente a arte de então se encarregava de reproduzir. A mulher é para essa artista, acima de tudo, humana, e seus auto-retratos compelem para a instauração de uma aura feminina que pensa, que cria, que faz e que vive com toda a intensidade suas possibilidades.

A representatividade de suas obras pode ser constatada por sua instauração na história da arte alemã, projetada para o mundo. Apesar de não ter feito parte do movimento expressionista, é através dele que Kollwitz chega ao Brasil e influencia determinantemente várias gerações de artistas brasileiros, como Lívio Abramo, Renina Katz e Carlos Scliar. Mário Pedrosa, na conferência proferida por ocasião da abertura da exposição de Kollwitz em São Paulo, em 1933, no Clube dos Artistas Modernos, assim se refere a ela:

É a artista da mulher proletária. A força popular institiva profunda desta, sua imensa capacidade de afeição e de sofrimento, aquela jovialidade e simpatia apesar de tudo diante da vida, tudo isso ela gravou na simplificação comovente da madeira, com uma rispidez quase hostil mas realçando pelo contraste a violência e a profundeza do sentimento expresso. (...) Até então, outros artistas, entre os quais os da escola naturalista, já tinham feito da vida das massas proletárias temas literários e plásticos. Mas era desconhecido na história da arte o artista que tivesse posto como finalidade de sua vida e de sua obra exprimir a vida coletiva e sentimental do proletariado como classe. Êste para ela é mais do que um assunto inexplorado e interessante; é a condição mesma de sua arte, a causa primária de sua sensibilidade. (1949, p.30,31).

Partidária de uma arte dinâmica, suas imagens trazem a marca da humanidade que carrega as dores do mundo. Seu caráter particular - retratos de situações reais - assume a dimen- 
são universal pela identificação com seu propósito perscrutante, que a aproxima cada vez mais de seus espectadores. Não por acaso, Kollwitz é reverenciada, ainda em vida, em países longínquos como China, Brasil e Rússia.

A recusa da beleza da arte convencional explicita o vigor de Kollwitz em contestar a contrastante desigualdade social. Sem jamais ter registrado sua vin-

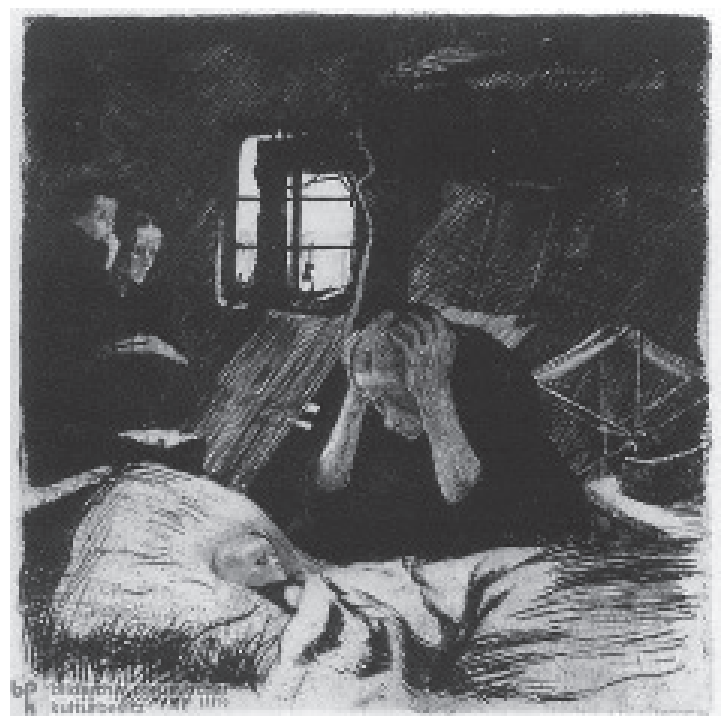
culação a um partido político, sua simpatia pelo socialismo "que deixa viver os homens" era evidente e suscita ainda hoje em nós, o questionamento acerca dos rumos da arte na contemporaneidade.

Longstreet, na apresentação de seu livro sobre a arte de Kollwitz, afirma que suas gravuras são hábeis em revelar formas gráficas poderosas, elas nos relembram, diz ele, das palavras do filósofo Santayana: "aqueles que não podem se lembrar do passado estão condenados a repeti-lo." (Longstreet, 1967, p.4)

No prefácio do catálogo da exposição Kthe Kollwitz: artista do povo, Fiona Griffith afirma que o fato de as gravuras de Kollowitz incluírem a herança romântica da santificação da vida humana, a profundidade da emoção e a crítica social lhe trouxe uma maior notoriedade.

Zigrosser, afirma que suas expressões eram sempre verdadeiras para ela e para seu tempo. Segundo ele,

"o ciclo Guerra representou a reação da mulher como esposa e mãe à guerra. Durante o desenvolvimento da concepção, através de todas as transmutações em desenhos, gravuras e litogravuras, era abstraído todo detalhe irrelevante, e finalmente emergiu como um drama puro de tensões emocionais. Era particularmente entrelaçado, plástico e monumental na forma 
e universal no sentimento." (ZIGROSSER: 1969, p. XIV).

O aparente antagonismo entre o universal e o particular é agora canalizado para a constituição da artista em estado pleno.

O contexto alemão no final do século XIX não era dos meIhores para os trabalhadores. A explosão demográfica ocorrida a partir de 1700 - atribuída à vacinação em massa, ao avanço da medicina, à valorização da alimentação cada vez mais variada e à água potável - concorria para um fluxo migratório para as cidades. A situação dos camponeses e dos artesãos se precarizou. Havia uma oferta excessiva de mão-de-obra.

Os trabalhadores, incluindo mulheres e crianças, trabalhavam por um salário abaixo do mínimo das fábricas, numa jornada que se estendia por até 17 horas, o que contribuiu para o surgimento do proletariado industrial. Os industriais 6 não adotavam nenhuma medida de segurança, muito menos instituíam seguridade ou aposentadoria. O superfaturamento no preço dos alimentos vendidos para os trabalhadores contribuía para o endividamento destes e para a degradação das condições de vida. O trabalho infantil no começo do século XIX retrata a face mais cruel da exploração. Assim descrita por Rivinius:

Havia casos em que crianças de quatro anos já tinham que contribuir com o seu quinhão para o sustento da família. Em geral, porém, as crianças começavam a trabalhar na idade de oito ou nove anos. Na região do Reno-Rur milhares de crianças eram empregadas em turnos diurnos e noturnos, num horário de até 14 horas. (...) não sobrava tempo para a educação escolar.

O descaso da inspeção por parte do setor público faz com que esse cenário de exploração se estenda por todo o século XIX. Nos anos de 1848 e 1849, as conseqüências da grave crise econômica que assola a Europa e a influência de ideais republicanos franceses incentiva, na Alemanha, uma insurreição popular, sobretudo em Berlim, que ficou conhecida como "Revolução de Março". Mas a força contra-revolucionária vence. Os problemas sociais advindos da industrialização coloca para o Estado alemão, unificado a partir de 1871, tendo como representante político o primeiro-ministro Otto Von Bismarck, o 
desafio de conciliar desenvolvimento e melhores condições de vida para a população. Esse quadro caótico exigiu do Estado algumas medidas.

Data desse período as primeiras greves gerais, que dão início à organização, ainda que tímida, da classe operária. Tal contexto propicia também a organização dos novos trabalhadores assalariados, que se inteiram da necessidade de se unirem em movimentos coletivos. O socialismo nascente influencia diretamente o movimento trabalhista e Ferdinand Lassalle funda, em 1863, a Associação Geral Alemã dos Operários Alemães que será propulsora nas décadas que se seguem, do surgimento de vários sindicatos trabalhistas. Em 1867, Wilhelm Liebknecht e August Bebel fundam um partido operário já sob a influência do pensamento marxista.

O presente quadro exige uma apreensão do passado para promover as transformações estéticas. Sobre a égide da modernidade há um avanço significativo no processo de ruptura com o realismo de então. Todas as angústias e deleites que a vida social trazia tornavam mais acentuadas as atitudes emergentes de fome e de miséria. Começa a surgir, sobretudo na classe intelectual e artística no final do século XIX, um movimento de reação ao ritmo industrial e uma tentativa de resgatar o dimensão humana que havia se perdido em meio ao aglomerado de máquinas. No âmbito das artes, todo esse processo se reflete na busca de novos elementos que promovam o aumento da sensibilidade. É importante ressaltar que todas essas mudanças não são abruptas, mas sim graduais, com algum avanço de um artista ou outro no uso de novos elementos estéticos.

Inserida na dinâmica da vida social, o comprometimento de Kollwitz com a causa operária afina-se com a arte no emaranhado da vida cotidiana dos operários, mesclada pela dor, o sofrimento, a violência e a privação. De certa forma, as variações das produções dos principais movimentos artísticos busca uma renúncia a toda forma elitista e autoritária de apropriação de obras que atendam a um mercado de consumo. É uma forma de resistência, de dizer não à estética capitalista que atenda a um mercado, de abolir a atitude meramente contemplativa e devocional ante à obras artísticas. 
É nesse contexto que,em 1893, Kollwitz expõe pela primeira vez. A gravura Na porta de Igreja é aceita na Exposição de Arte Livre em Berlim, juntamente com obras de Eduard Munch, Max Liebermann e outros.

Obviamente uma arte engajada encontraria resistência por parte da classe política dominante. O impacto causado pela técnica e a temática adotada pela artista fez com que a reação ao seu trabalho fosse, muitas vezes, de escárnio. Simone narra em sua obra Käthe Kollwitz, que o Imperador Guilherme suspendeu o prêmio atribuído a Kollwitz pela série A Revolta dos Tecelões, concedido pela Grande Academia de Berlim em 1898, por considerar sua obra "arte de esgoto", (2003, p.24) e ainda que a Imperatriz se negou a participar de uma exposição em Berlim pois esta estava expondo "obras provocativas" (idem, p.24) de Kollwitz. As obras em questão eram da série Retratos da Miséria, da qual um de seus desenhos, Trabalho Domiciliar, ilustrou o cartaz da exposição.

Como resistência à interferência da política na arte, um gru-

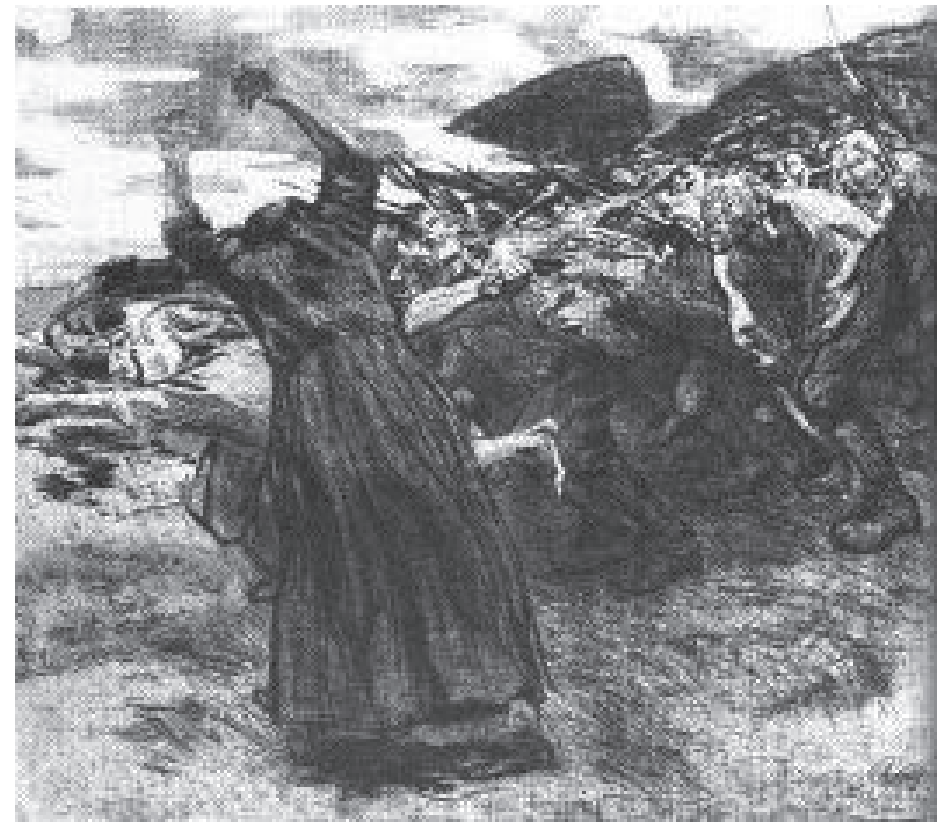


pos de artistas funda a Secessão de Berlim, presidida pelo artista Max Libermann. Esse movimento é extremamente aberto aos mais variados estilos e Kollwitz faz parte dele.

Na primeira década do século $X X$, a perseguição aos artistas chamados sociais continua mas com um dado novo: o anti-semitismo. Como resistência à ordem instituinte e fiel às suas convicções, Kollwitz cria uma série intitulada Retratos da Miséria, no período de 1908 a 1911. De 1902 a 1908 a artista trabalha na série Guerra dos Camponeses. Contribui com a revista satírica Simplicissimus enviando desenhos no período entre 1907 e 1909.

Kollwitz, a princípio apoiou a Primeira Guerra Mundial, mas com a morte do filho Peter, em 1914, em combate em Flandres, a artista redimensiona seu posicionamento. A partir daí, a presença da "morte" em suas gravuras se torna uma constante. Também data do início do século suas primeiras incursões pela escultura.O interesse por essa nova arte leva a artista a freqüentar um curso em Paris. Visita por duas vezes o ateliê de Rodin. Porém, no conjunto de sua obra, essa técnica nunca irá se sobrepor à gravura. A experimentação de estilos conduz Kollwitz à xilogravura e em 1919, quando chamada pela família de Karl Liebknecht para retratá-lo em seu leito de morte, ela inicialmente faz uma gravura em metal, depois uma litogravura e finalmente decide-se pela xilogravura, sua primeira incursão nessa técnica, e dá a ela o nome Em memória a Karl Liebknecht. Entre 1922 e 1923 faz o ciclo Guerra, com sete xilogravuras.

Nos anos vinte, já com mais de cinqüenta anos, Kollwitz cria cartazes para inúmeras campanhas de instituições nas quais ela estava, direta ou indiretamente, ligada. Cito algumas: Ajuda Internacional do Operário, na Rússia; União Nacional para a Proteção de Prisioneiros Civis e de Guerra Alemães; União Sindical Internacional e do Movimento Socialista dos Operários, Movimento do Partido Comunista para a anulação do decreto do aborto, etc.

Com a ascensão de Hitler ao poder, Kollwitz se negou a sair do país como o fizeram vários de seus amigos, mas teve que conviver com um "exílio interno". Proibida de expor, destituída 
do cargo de diretora do ateliê de artes gráficas da Academia de Belas -Artes de Berlim, cargo que exercia desde 1928, Kollwitz e seu marido Karl são constantemente ameaçados pela Gestapo. Mas a artista, apesar de ver suas obras retiradas dos museus públicos e das galerias, não é incluída dentre aqueles que fariam parte da famosa exposição chamada Arte Degenerada, em 1937.

A contestação da artista ao modelo político que dilacera o humano, sobretudo no cotidiano da fábrica, explicita o potencial narrativo de sua obra que denuncia o Estado e sua indiferença para com o proletário que fica reduzido a um nada, um sem lugar. A ausência de elementos da natureza, o vazio de detalhes no espaço povoado pela dor e o sofrimento, retrata uma ausência plena de sentido, uma ausência que quer significar nos traços fortes, no contraste do claro-escuro, nas linhas secas das litogravuras.

Se, como nos diz Martins, "Sentir-se provocado, incomodado, deslocado de estéticas convencionais, é sem dúvida ampliar trocas e experiências de viver socialmente. É, também refletir sobre as práticas de construir pequenos gestos cotidianos, movendo temporalidades, concretizadas em trajetórias humanas, experiências e práticas concretas . (Martins et al.,2005, p.10), a representação da união no coletivo do operariado, reforça a crença da artista no socialismo e no comunismo como vias de condução do ser a um mundo mais humano. A riqueza de sua obra reside em mostrar-se na ausência, no encadeamento de uma posição critica que nos permite identificar na expressão artística os elementos da expressão humana perdida e, o que

\section{Referências}

DUFRENNE, Mikel. Estética e filosofia. São Paulo: Perspectiva, 1998. 266p.

KOLLWITZ, Käthe : artist of people. Catálogo de exposição. Londres, The South Bank Centre, 1995. 48p.

KOLLWITZ, Hans. (edit.) The diary and letters of Kaethe Kollwitz. Illinois, USA: Northwestern University Press, 1988. 260p.

LONGSTREET, S. (apres.). The drawings of Kaethe Kollwitz. Alhambra, California: Borden Publishing Company, 1967. 48p.

MARTINS, José de Souza; ECKERT, Cornelia; NOVAES, Sylvia Caiuby (orgs.). 
O imaginário e o poético nas Ciências Sociais. Bauru, SP: EDUSC, 2005. $315 p$.

PEDROSA, Mário. As tendências sociais da arte e Kaethe Kollwitz. In:

Arte necessidade vital. Rio de Janeiro: CEB, 1949. p.7-34

RIVINIUS, J. O movimento social na Alemanha no século dezenove. In: KOLLWITZ, Käthe. Gravuras, esculturas. Stuttgart: Institut fur Auslandsbeziehungen, 1986. 123p. p.13-24

SIMONE, Eliana de Sá Porto de. Käthe Kollwitz. São Paulo: EDUSP, 2005. $232 p$.

ZIGROSSER, C. Prints and drawings of Käthe Kollwitz. New York: Dover Publications, 1969.

\section{RITA MÁRCIA MAGALHÃES FURTADO}

Graduada em Pedagogia pela UCG (1987), mestre em Educação pela UFG (2000) e doutora em Educação pela Unicamp (2007). Atualmente é professora convidada da Universidade Católica de Goiás e professora substituta da Universidade Federal de Goiás. Tem artigos publicados na área de Educação, Estética, Infância e Artes. Email: rmmfurtado@uol.com.br 